\title{
Sağlık Kuruluşlarındaki Kurumsal Kaynak Planlama Sürecinin Değerlendirilmesi
}

\author{
Fedayi YAĞAR*
}

\section{$\ddot{O} \mathbf{z}$}

Bu çalışmada sağllk kuruluşlarındaki kurumsal kaynak planlama süreci (Enterprise Resource Planning - ERP) değerlendirilmiştir. ERP, bir kurumda yer alan birimler arasındaki koordinasyonu sağlayan ve bu koordinasyonu modül tabanlı uygulayan bir yazılım paketidir. Başarılı olunması için üst yönetimin desteği ve proje ekibinin süreci benimsemesi kaçınılmazdır. Sağlık kuruluşlarındaki ERP uygulamaları ile ilgili yapılan çalışmalarda, bu sistemin sağlık hizmetleri için büyük önem arz ettiği, bu sistem ile birlikte bilgilerin zamanında ve daha erişilebilir hale geldiği, kuruma teknolojik anlamda güç kattığı, çalışanların performansını etkileyebildiği, hastaların kabulü ile ilgili süreçlerin daha iyi bir şekilde organize edildiği ve sınırlı olan kaynakların verimli bir şekilde kullanılabildiği gözlemlenmiştir. Türkiye'de kamu kuruluşlarında kullanılmadığı, sadece birkaç özel sağlık kuruluşunda kullanıldığı görülmüştür.

Anahtar Kelimeler: Kurumsal kaynak planlama, sağlık kuruluşları, verimlilik.

\section{Efficient Use of Limited Resources in Health Institutions: Enterprise Resource Planning}

\begin{abstract}
In this study, the Enterprise Resource Planning (ERP) in health institutions was evaluated. ERP is a software package that provides coordination between units in an institution and applies this coordination on a module basis. In order to be successful, it is necessary that the support of the senior management and the adaptation of the project team to the process. In studies on ERP applications in health institutions, it has been observed that this system is of great importance for
\end{abstract}

Derleme Makale (Review Article)

Geliş / Received: 21.05.2021 \& Kabul / Accepted: 01.07.2021

DOI: https://doi.org/10.38079/iqusabder.940543

${ }^{*}$ Arş. Gör. Dr., Kahramanmaraş Sütçü İmam Üniversitesi, İ̈BF, Sağlık Yönetimi Bölümü, Kahramanmaraş, Türkiye. E-posta: fedayiyagar@hotmail.com ORCID https://orcid.org/oooo$\underline{0002-3436-6583}$ 
health services, information becomes timely and more accessible with this system, it adds technological strength to the institution and can affect the performance of employees, and the processes related to the admission of patients are better organized and limited resources can be used efficiently. It has been observed that it is not used in any public institutions in Turkey, but only in a few private health institutions.

Keywords: Enterprise resource planning, health institutions, productivity.

\section{Giriş}

Günümüzde kurumların kaynaklarını etkin ve verimli bir şekilde kullanmasını sağlayan ve kuruma maliyet ve rekabet gibi noktalarda avantaj sağlayan önemli etmenlerden birisi sahip olunan bilginin etkili bir şekilde kullanılmasıdır. Bilgi analitiği, yaşamın neredeyse her alanında yaygın kalite ve verimlilik iyileştirmeleri sağlamıştır. Dahası, teknolojik gelişmelerin ve bilgi sistemlerinin entegre sistemlere yönelimi düşünüldüğünde sağllk sektörü de bir istisna olmaktan çıkmaktadır . Özellikle günümüzün çalkantılı iş ortamında, daha verimli ve stratejik yönetim kararları için uygun ERP sistemi gereklidir. Aynı şekilde, karşılaştığımız salgını (COVID-19) dikkate aldığımızda, bir sağlık kuruluşunun salgın ile mücadeledeki başarısının temelinde kaynakların yeterliliğinin ve verimli kullanımının yer aldığı ve ERP’nin önemli bir rol oynadığı̈ görülmektedir. Sınırlı da olsa bu süreçte yapılan bazı araştırmalar ERP’nin salgın sürecinde olumlu yönde katkı sağladığına dair kanıtlar sunmaktadır²,3.

Başarılı bir ERP benimseme planlaması ve uygulaması, karar vericilerin sağlık hizmetleri sistemlerinin karşılaştı̆̆ birçok zorluğun üstesinden gelmesine izin verebilir. Bu tür başarılı planlama ve uygulama, sağlık hizmetleri sistemlerinde stratejik ERP oluşturmak için benzeri görülmemiş firsatlar sunabilir4 . Diğer yandan, hizmet sunanların (hekim, hemşire ve yönetici gibi) doğru zamanda bilgiye ulaşması gerekliliği, sağlık sektörünün heterojen bir yapıya sahip olması ve bireyin hayatının söz konusu olması gibi sebeplerden dolayı farklı yapılar arasında iletişim kurulması ve bütünleşik bir yaklaşımın olması gerektiği kaçınılmaz bir nokta olarak karşımıza çıkmaktadır. Bu noktada ilgili yazılımların seçiminin nasıl olması gerektiği ve hastanelerdeki yapının nasıl olduğu büyük önem arz etmektedir. Ayrıca bu sistemin başarılı olabilmesinde yönetimin desteğinin sağlanması, çalışanlara sürekli olarak eğitimler verilmesi, çalışanların da bu 
sistemin önemine inanması ve değişime karşı direnç göstermemesi de vurgulanması gereken hususlardır.

Ulusal literatür incelendiğinde, ERP ile ilgili çok az çalışmaya yer verildiği ve sağlık kuruluşları özelinde bu modelin çok fazla incelenmediği görülmüştür. Bu derleme ile birlikte ERP'nin tanımı yapılmış, sistemin avantajları ve dezavantajları incelenmiş, yazılımların seçilmesinde ve uygulanmasında nelere dikkat edileceği, yazılımlarda en az hangi modüllerin yer alacağı, ERP'nin başarısını etkileyen faktörlerin ne olduğu ve sağlık kuruluşlarındaki ERP süreci değerlendirilmiştir.

\section{ERP'nin Tanımı}

Günümüzde bilinen kurumsal kaynak planlama (ERP) sistemleri, 1960 ve 1970'te kullanılan malzeme ihtiyaç planlaması ve 1980’lerde üretim kaynak planlaması ile ortaya çıkmış ve o tarihten günümüze kadar uzun bir yol kat etmiştir5. ERP sistemi, temel süreçler (üretim planlama ve kontrol ve depo yönetimi gibi) ve bir işletmenin ana idari işlevleri (muhasebe ve insan kaynağı yönetimi gibi) için entegre iş çözümleri içeren özelleştirilebilir, standart bir uygulama yazılımıdır ${ }^{6}$. Kısacası, şirketin tüm verilerini yönetmek ve ihtiyaç duyan kişilere ihtiyaç duyduklarında bilgi sağlamak için kullanılan yazılım araçlarıdır. Bu sistemler, kuruluşların tedarik zinciri ile ilgilenmesine yardımcı olur. Bu zincirde alıcılar, envanter yönetimi, müşteri sipariş yönetimi, üretim planlama ve yönetme, nakliye, muhasebe, insan kaynakları yönetimi ve modern bir işletmede yer alan diğer tüm faaliyetler yer almaktadır7.

ERP sistemleri ile birlikte güvenilir bilgi erişiminin olacağı, işlem fazlalığından kaçınılacağı, teslimat ve devir süresinin azalacağı, maliyetlerin azalacağı, kolay bir adaptasyonun olacağı, sürdürülebilirliğin artacağı, bazı modüller ile birlikte küresel destek sağlayacağı, e-ticaret ve e-iş gibi durumlarda fayda sağlanacağ belirtilmiştir. Dezavantajları açısından bakıldığında ise, zaman alan bir süreç olduğu, pahalı olduğu, modüllerin uymama durumunun olduğu, satıcıya bağımlılık yarattığı, özelliklerinin çok fazla olduğu ve karmaşıklık oluşturduğu, küresel ölçekte olduğu, ölçeklendirme sıkıntısının ortaya çıktığı ve ERP kapasitesinin sürekli genişletildiği vurgulanmıştır8. Başka bir çalışmada ise benzer sonuçlar ifade edilmiş ve kullanımının kolay olduğuna, kurulan bütün fonksiyonlar arasında entegrasyonu sağladığına, tedarikçiler ve müşteriler arasında online iletişim sağlayabileceğine, özelleştirmenin bir seçenek 
olduğuna, uygun bilgiye zamanında ulaşlabildiğinden kararların ve süreçlerin geliştirilebileceğine, internet ara yüzlerinin bir seçenek olduğuna ve hataların azaltılabileceğine dikkat çekilmiştir. Dezavantaj olarak ise, değişime karşı örgütsel dayanıklılığın yüksek olabileceği, köklü değişimlerin büyük bir maliyet yükü getireceği, sistemden kaynaklanan veri hatalarının olabileceği, sürdürülebilmesinin maliyetli olabileceği ve zaman alacağı belirtilmiştir 9 .

ERP ile ilgili karşılaşılan önemli sorunlardan bir tanesi de, verilerin güvenliğinin nasıl sağlandığıdır. Bu noktada bulut teknolojisi devreye girmektedir. Kurumlar tarafından ERP ile elde edilen verilen bulut teknolojisi ile saklanmaktadır. Hofmann ve Woods ${ }^{10}$ tarafından yapılan çalışmada bulut modelinin en büyük zorluklarından birisinin güvenlik olduğu ve genellikle duygusal yaklaşıldığı belirtilmiştir. Sınırlı kaynaklara sahip küçük bir işletme için bulut teknolojisinin kullanımının yeterli olduğu, daha büyük kurumlar için ise "İnsan Hizmetleri Sağlık Sigortası Taşınabilirliği ve Hesap Verebilirlik Yasası (HIPAA)" gibi düzenlemelerin olduğu belirtilmiştir. Benzer bir şekilde Peng ve Gala $^{11}$ tarafından yapılan çalışmada kurumların bulut teknolojisine tereddütle yaklaştığı ve kurumlar arasında yasal düzenlemeler yapıldığı ifade edilmiştir. Aynı çalışmada 16 ERP danışmanını kapsayan nitel bir araştırma yapılmıştır. Bulut teknolojisi ile ilgili kurumlara sunulan tekliflerin ekonomik ve teknik açıdan avantajlı olduğu fakat teknolojinin benimsenmesi noktasında zorluklar yaşandığı, hukuki ve teknik karmaşıkların oluştuğu vurgulanmıştır.

\section{ERP Yazılımının Seçilmesi ve Uygulanması}

ERP sistemlerin temelini oluşturan yazılımların seçimi çok önemlidir. Bu yazılımların seçimine geçmeden önce, bu yazılımların içinde hangi modüller olması gerektiği kısaca açıklanmalıdır. Bilgi sistemleri çevresi ile entegre bir şekilde çalışabilmesi için ERP içerisinde yer alması gereken modüller; satış ve dağıtım modülü, malzeme yönetim modülü, üretim planlama modülü, kalite yönetim modülü, tesislerin bakımı modülü, varlık yönetim modülü, insan kaynakları modülü ve proje sistem modülüdür. Finansal hesaplamalar ve kontrol modülleri ise bu sekiz modülün dışında tutulmuştur. Kurumdaki her eylemin şirketin finansal pozisyonu üzerinde etki yaratacağı ifade edilmiştir. Son olarak, tüm bu modüllerdeki akışı inceleyen bir iş akışı modülünün olması gerektiği vurgulanmıştır ${ }^{12}$. Yazılımın seçilmesi noktasına gelindiğinde ise, vizyonun yaratılmasına, bir özellik (işlev) listesinin oluşturulmasına, yazılım adaylarının 
listesinin oluşturulmasına, listenin daraltılmasına (4 -6 arasında ciddi aday), tekliflerin talep edilmesine, tekliflerin değerlendirilmesine, 2 ya da 3 final teklifinin seçilmesine, finalistlerin paketlerini sergilemesine, kazananın seçilmesine, yatırımın yapılmasına, sözleşmelerin yapılmasına, uygulamadan önce pilot bir çalışmanın olmasına ve son olarak yazılımın seçimi ile ilgili gerekçelerin yazılmasına sırası ile çok önem verilmesi gerektiği belirtilmiştir. Ayrıca seçilen yazılımın uygulanmasında bazı önemli adımların takip edilmesi gerektiği ifade edilmiştir. Bunlar; şimdiye kadar olan uygulama sürecini gözden geçirmek, yeni donanımı kurmak ve test etmek, yazılımı kurmak ve bilgisayar odasında pilot uygulamasını yapmak, sistem eğitimine katılmak, konferans odasında bir pilot uygulaması eğitimi yapmak, güvenliği kurmak ve gerekli izinleri almak, veri köprülerinin sağlamlığını ve doğruluğunu sağlamak, politika ve prosedürleri belgelemek, bütün organizasyonu ya tamamen ya da aşamalı bir yaklaşımla çevrimiçi hale getirmek, kutlama yapmak (projenin ne kadar önemli olduğunu göstermek) ve sürekli iyileştirmeyi sağlamaktır ${ }^{13}$.

Türkiye'de ERP'yi aktif bir şekilde kullanan kurumlardan bir tanesi de Medical Park Hastaneler Grubu'dur. Kurum tarafından yapılan açıklamada ERP yazılımının seçilmesi ve uygulanması sürecinde izlenen adımlar şu şekilde sıralanmıştır: (1) ERP ihtiyacının sorgulanması, (2) yönetim danışman şirketinin seçilmesi, (3) ERP uygulama kararı, (4) ERP’nin seçimi ve (5) uygulama yapacak iş ortağının seçilmesi. Sonraki süreçte hastaneler grubu içerisinde yer alan tüm kurumların katılımı ile workshoplar düzenlenmiş, hastanelerdeki farklı iş süreçleri tek tek analiz edilmiş, teknik ve fonksiyonel karşılaştırmalar sonucunda ERP seçilmiştir. Aynı şekilde bu süreçte üst yönetimin beklentileri çalışanlara açık bir şekilde iletilmiş, sahadaki tecrübeli çalışanlar projeye atanmış, özel olarak çalışma alanı tahsis edilmiş ve gerekli olan ihtiyaç listesi hazırlanmıştır. Son olarak, merkezde 25, hastanelerde 102 anahtar kullanıcı belirlenmiş ve altı ay içerisinde tüm kurumlar sürece aktif olarak dahil edilmiştir. Hastanede kullanılan Medin (hastanecilik uygulamaları ve medikal muhasebe) ve Oracle EBS+Bordro (mali işler, finans, hazine, satın alma, envanter, temel insan kaynakları, eğitim, performans yönetimi, self servis ve bordro) sistemleri bir araya getirilerek entegrasyon arayüzleri oluşturulmuştur ${ }^{14}$. 


\section{ERP Uygulamasının Başarısını Etkileyen Faktörler}

ERP uygulamasının başarılı olabilmesi için stratejik hedeflerin açık bir şekilde anlaşılması, yönetimin tamamının bağlılık göstermesi, çok iyi bir şekilde proje yönetimi, örgütsel değişim yönetimi, büyük bir uygulayıcı takım, veri güvenliği, kapsamlı bir eğitim ve performans ölçümlerine odaklanma gerekmektedir ${ }^{13}$. Aşağıda verilen Şekil 1'de ise, bu süreç açık bir şekilde gösterilmiştir.

Şekil 1. ERP uygulamasındaki başarı faktörleri ${ }^{6}$

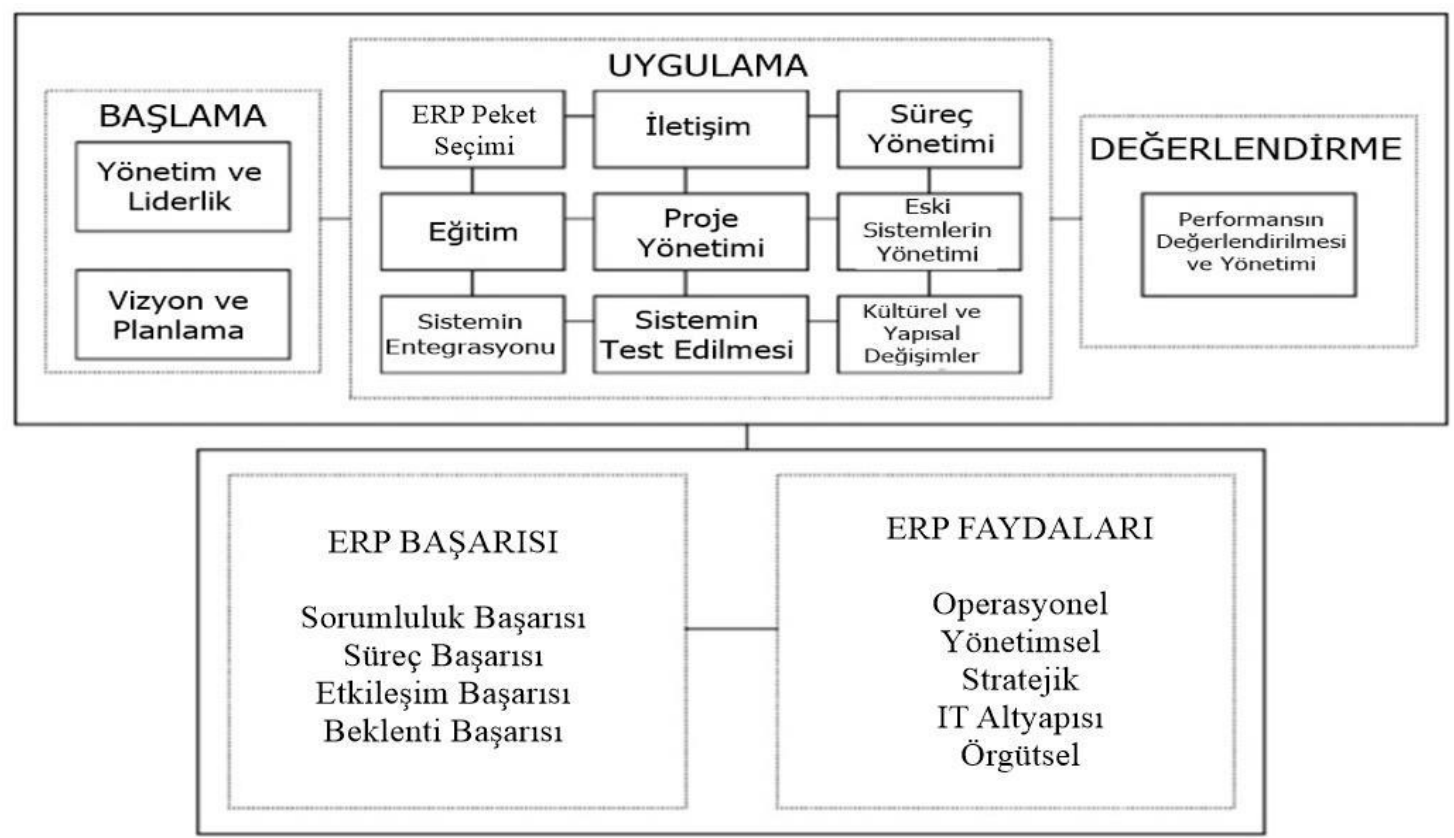

Şekil 1'de ERP ilk olarak 3 açıdan (kurma, uygulama ve değerlendirme) incelenmiş ve sonrasında oluşması beklenen başarılar ile faydalar açıklanmıştır. Kurma (başlama) aşamasında yönetim, liderlik, vizyon ve planlamanın olması; uygulama aşamasında ERP paket seçimi, iletişim, süreç yönetimi, eğitim, proje yönetimi, eski sistemlerin yönetimi, sistemin entegrasyonu, sistemin test edilmesi, kültürel ve yapısal değişimlerin olması ve değerlendirme aşamasında ise performansın değerlendirilmesi ile yönetilmesinin olması gerektiği vurgulanmıştır. Bu aşamalar sonucunda sorumluluk, süreç, etkileşim ve beklenti başarısının oluşacağı ve bu başarılar ile birlikte operasyonel, yönetimsel, stratejik, bilgi teknolojisi altyapısı ve örgütsel anlamda fayda elde edinileceği belirtilmiştir. 
ERP'nin başarısını etkileyen faktörlere ilişkin kanıtlar yapılan bazı araştırmalarda ortaya konulmuştur. Örneğin Somers ve Nelson ${ }^{15}$ tarafından yapılan çalışmada 22 faktör olduğuna vurgu yapılmış ve bu faktörler doğrultusunda 86 kurum incelenmiştir. Bu kurumlarda çalışan üst düzey yöneticiler ile yapılan görüşmelerden elde edilen verilere göre kritik başarı faktörleri sıralanmıştır. Bütün yönetiminin desteğinin olması, proje takımındaki uyumluluk ve departmanlar arası ilişki ortalama açısından ilk 3 sırada yer almıştır. Son 3 sırada ise danışmanların kullanımı, satıcıların araçlarının kullanımı ve satıcı ile ortaklık yer almıştır. Ehie ve Madsen ${ }^{16}$ tarafından 36 kuruluş üzerinde yapılan çalışmada ERP'nin uygulanmasını etkileyen faktörler incelenmiştir. Çalışma kapsamında değerlendirilen proje yönetimi kriterleri, ERP projesinin değerlendirilmesi, değişim mühendisliği süreci, toplam yönetici desteği, maliyet/bütçe ve danışma servisleri faktörleri ile ERP uygulaması arasında anlamlı bir ilişki bulunmuştur. Bradford ve Florin ${ }^{17}$ tarafından yapılan çalışmada ise, yeniliklerin yayılma faktörlerinin ERP üzerindeki etkisi araştırılmıştır. Amerika'daki bir yazılım şirketinin (Systems Analysis and Program Development -SAP) kullanıcı grubunun 51 yönetici üyesi üzerinde yapılan çalışmada üst yönetimin destek ve eğitiminin kullanıcı memnuniyeti ile pozitif yönde ilişkili olduğu, ERP'nin algılanan karmaşıklığı ve rekabet baskısı ile de negatif bir ilişki olduğu görülmüştür.

\section{Sağlık Kuruluşlarında ERP}

Sağlık kuruluşlarında hizmet sunumu sürecinde çok fazla bilgi ile karşı karşıya kalınmaktadır. Bilgiler, kontrol ve planlama gibi departmanların işlevlerine göre farklı kullanım alanlarına sahiptirler. Bu nedenle, bu bilgiye uygun birimler tarafından doğru zamanda erişilebilir kılınması önemlidir ${ }^{18}$. Bu bağlamda başarılı bir ERP'nin benimsenmesi planlaması ve uygulanması, karar vericilerin sağlık bakım sistemlerinin karşılaştı̆̆ı birçok zorluğun üstesinden gelmesine olanak sağlayabilir. Böyle başarılı bir planlama ve uygulama, sağlık bakım sistemlerinde stratejik ERP oluşturmak için benzeri görülmemiş firsatlar sunabilir. İmalat ve sağllk hizmetleri arasında önemli farklar olmasına rağmen, daha önce üretim için uygulanan ve uygulamaya konulan ERP sağlık hizmetlerinde de kullanılabilmektedir. Teknoloji ve örgütsel paradigmaların değişmesi nedeniyle, sağlık ortamlarında ERP; finansman, insan gücü, kapasite, gelir ve kabul kaynakları fonksiyonları ile birleştiğinde daha sağlam bir hale gelebilmektedir. $\mathrm{Bu}$ karmaşık süreçlerin içerisinde oluşturulan başarılı bağlar, sağlık hizmetlerinde iş 
performansını etkileyen kritik bir işlev görebilecektir ${ }^{4}$. Roth ve Van Dierdonck ${ }^{19}$ tarafından yapılan çalışmada hastaneler için bir kurumsal kaynak planlama çerçevesi oluşturulmaya çalışılmış ve bu yapı aşağıda verilen Şekil 2'de basit bir yapı ile gösterilmiştir.

Şekil 2. Hastanelerde kurumsal kaynak planlaması ${ }^{19}$

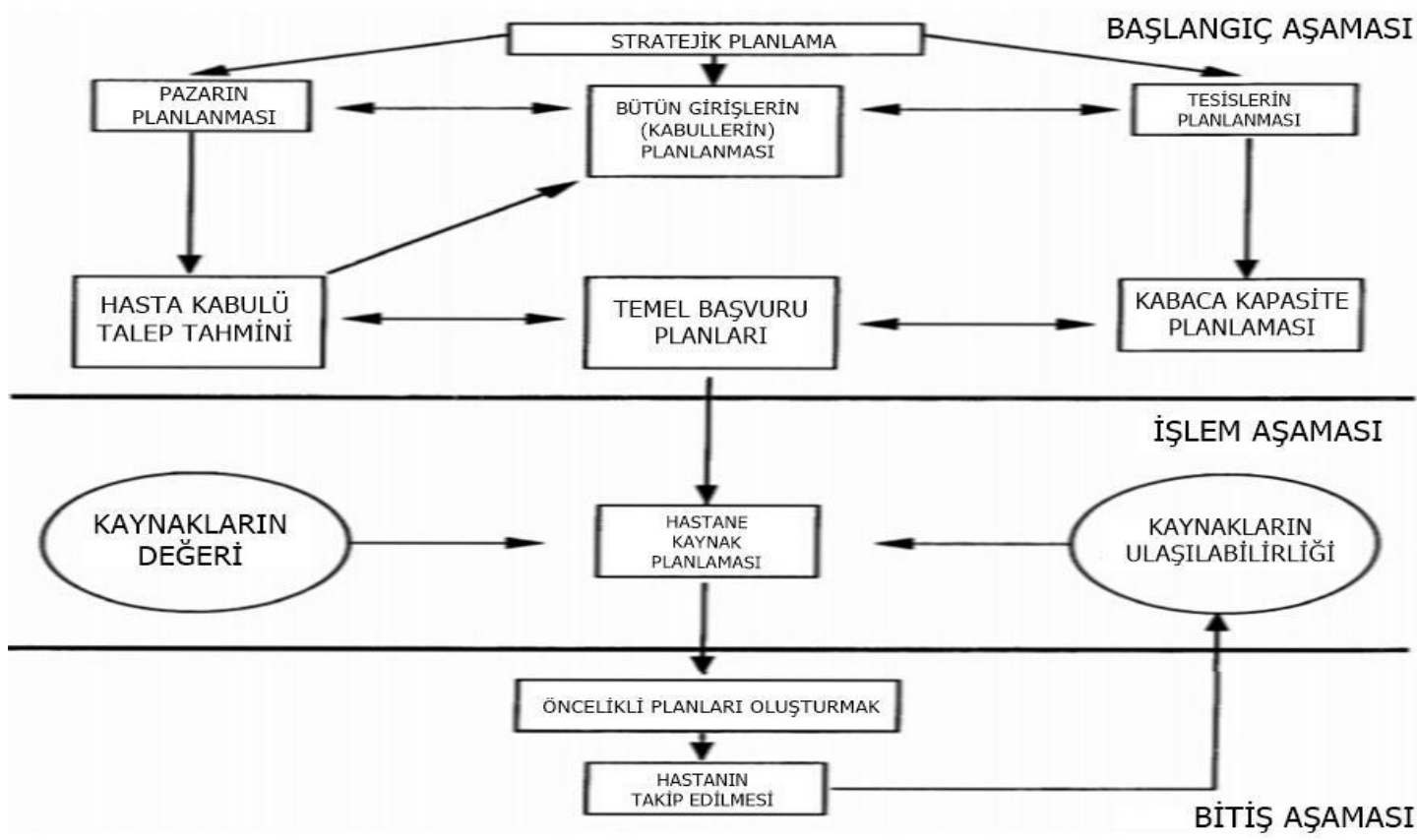

Şekil 2'de görüldüğü üzere, hastanelerdeki kurumsal kaynak planlaması üç aşamada incelenmiştir. Birinci aşamada stratejik planlama ile sürecin başladığı görülmüştür. $\mathrm{Bu}$ planlama ile birlikte pazarın, bütün hasta kabullerinin ve tesislerin planladı̆̆ı; pazarın planlaması ile birlikte hasta kabulü talep tahminin yapıldığı; tesislerin planlanması ile de genel olarak tesislerin planlamasının yapıldığı ve bunların temel başvuru planlarını oluşturduğu belirlenmiştir. İkinci aşamada, hastane kaynak planlamasının oluştuğu ve bu aşamada kaynakların değerinin ve ulaşılabilirliğinin de bu planlama üzerinde etkisinin olduğu gözlemlenmiştir. Bitiş aşamasında ise, hastane kaynak planlamasına bağlı olarak öncelikli planların oluşturulduğu ve daha sonrasında ise hastanın takip

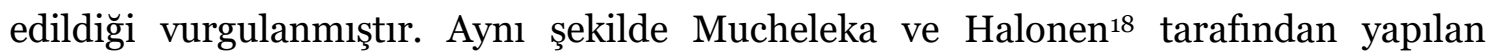
çalışmada ise, merkezde ERP veritabanın olduğu bir yapı düşünülmüştür. Bu yapıda ERP veritabanına bağlı olarak çalışan finansal yönetim, operasyonel yönetim, envanter 
yönetimi, tedarikçi yönetim, insan kaynakları yönetimi ve danışmanlar olduğu belirtilmiştir.

ERP için sağlık kuruluşlarında gerekli olan planlama ve kontrol süreçlerine bakıldığında; planlama çerçevesinin ilk aşaması hasta grubu ile ilgilidir. Bu aşamada teşhis ve tedavi aşamaları ayırt edilebilmelidir. Bu aşamalarda yapılacak işlemlerin farklı olması (her hasta için farklı bir akışın olması), kaynakların etkili bir şekilde kullanılması gerekliliği ve çalışanların performansını en iyi şekilde kullanması gibi etkenler bu ayrımın önemi ortaya koymaktadır. $\mathrm{Bu}$ ayrımdan sonra düşünülen ikinci aşama, kaynakların planlanması ve kontrolüdür. Burada hangi hasta grubu için hangi kaynakların kullanıldığı ve bu kaynakların hastanede olup olmadığı belirlenir. Bu çerçevede son aşama, hasta hacim planlaması ve stratejik planlamanın yapılmasıdır. Burada hastanedeki verilen hizmetler ile kaynaklar arasındaki denge incelenmekte, gelecekte hangi hasta grubunun daha çok gelebileceği noktasında tahmin yapılmakta ve stratejiler geliştirilmektedir. İkinci çerçeve olarak planlamadaki belirsizlik açıklanmaya çalışılmıştır. Sektör yapısı gereği hastalıkların ya da acil durumların ne zaman ortaya çıkacağının belirsiz olduğu ifade edilmiş ve ERP'nin tahmin noktasında belirli bir noktaya kadar olanak sağladığına vurgu yapılmıştır. Ayrıca var olan veriler üzerinden bazı yöntemler aracılığı ile bu tahminlerin yapılmaya çalışıldığı fakat bu yöntemlerinde yetersiz kaldığı belirtilmiştir. Bu hesaplamalarda değişken ve rastgele oluşun hesaplanmasının veya reaktif karar verme (hastaların aldığı randevular üzerinden tahmin yapmak gibi) yöntemlerin kullanılmasının etkili olacağı söylenmiştir. Ayrıca bu süreçte personel çizelgelemelere de önem verilmesi gerektiği ifade edilmiştir. Yukarıdaki ifadelerden anlaşılacağı üzere, hastanelerin tüm organizasyon için bir ERP kavramı kullanamayacağı (özellikle belirsizliği planlama noktasında) açıktır. Bununla birlikte ERP, organizasyonun mekanik özelliği olan kısmı, ayrıntılı planlama için birçok olanak sunmakta ve fayda sağlamaktadır²0.

ERP, idari ve klinik işlemlerin maliyetlerini azaltmayı ve aynı zamanda tüketicilerine daha iyi hizmet sunmayı planlayan hastanelere etkili bir çözüm sunmaktadır. Operasyon kontrolünü ve operasyonları düzene sokarak hastane yöneticilerine yardımcı olur. Hasta bilgilerini toplama ve alma işlemlerini otomatik hale getirdiği için hasta bakımının taleplerine daha iyi yanıt verir. Otomatik ve akıllı bir hasta bilgisi akışını sağlayarak, hastanelerin ve doktorların hastalarına daha iyi hizmet vermelerini sağlar. Ek olarak, 
ERP kolay hasta kayıtları yönetimi, azaltılmış evrak işi, çeşitli departmanlar arasındaki daha hızlı bilgi akışı, daha fazla örgütsel esneklik, güvenilir ve zamanında bilgi, minimum envanter seviyeleri, azaltılmış israf, azaltılmış bekleme süreleri gibi ve hastalar için kayıt süresinin azalması gibi yararlar da sağlamaktadır. Bu dolaylı yararlar, hastanenin imajının iyileştirilmesine ve artan rekabet ortamında avantaj sağlamasına yol açacaktır. $\mathrm{Bu}$ sistemin, hastanenin karlılı̆̆ını da artırabileceği söylenebilir²1. Örneğin, İsrail'de yapılan bir araştırmada kamu sağlık kuruluşlarının bakımı için sekiz performans göstergesi ERP'ye entegre edilmiş ve performansa dayalı bir model geliştirilmesi hedeflenmiştir. Modelin 42 sağlık kuruluşundan oluşan bir örneklemde uygulanması, \%25 artan verimlilik ile sonuçlanmıştır ${ }^{22}$. Pakistan'da 279 tıp uzmanını kapsayan bir araştırmada ERP’nin sağlık hizmetleri kalitesi üzerindeki etkisi incelenmiştir. Sonuçlar, bir kurumsal planlama sisteminin kullanımının sağlık hizmetlerinde bireyler, kurumsal bilgi kalitesi ve sistem kalitesi üzerinde olumlu bir etkisi olduğunu ortaya koymuştur. Ayrıca, iyi uygulanmış bir ERP sisteminin daha iyi sistem çıktısı ile sonuçlandığı ve sağlık uzmanlarının daha iyi sağlık hizmeti kalitesi sunmasını sağladığını belirtmiştir

Sağlık kuruluşlarının kendine has özellikleri ile nedeni ile ERP'nin uygulanması sürecinde bazı dezavantajlar ile karşılaşılabilmektedir. Örneğin, İspanya'da yapılan bir araştırmada klinik (Tıbbi, Hemşirelik) ve klinik olmayan (Ekonomik-Mali, Muhasebe) farklı grupların heterojen doğası gereği, ERP'nin uygulanması sürecinde olumsuz bir etkiye neden olduğuna vurgu yapılmıştır²3. Aynı şekilde, yapılan başka bir çalışmada, sistematik bir analiz ile sağlık alanında yapılan 24 makale incelenmiş ve ERP'nin gelişimine neden olan faktörler değerlendirilmiştir. Gelişmekte olan ülkelerde kültürel yapının ve teknolojinin sorun olduğuna, yarı gelişmiş ülkelerde teknolojinin ve ekonominin sorun olduğuna ve son olarak gelişmiş ülkelerde hizmette sorun olduğuna, eğitim ve yazılımdan alınan hizmetlerin kalitesinden dolayı sorunlar yaşandığına vurgu yapılmıştır ${ }^{24}$. Genel olarak değerlendirildiğinde, ERP sistemlerinin sıkı usullere sahip olduğu ve değişmesinin kolay olmadığı, bilgiler paylaşıldığı için daha şeffaf hale geldiği, değişimlere karşı çalışanların direnç gösterebildiği ve bu sistemlerin maliyetli olduğu da belirtilmektedir ${ }^{18}$.

Türkiye'ye bakıldığında, ERP yerine daha çok Hastane Bilgi Yönetim Sistemlerinin (HBYS) kullanıldığı görülmektedir. HBYS programlarında stok yönetimi, insan kaynakları yönetimi, müşteri ilişkileri yönetimi ve finans gibi birçok alt modül 
bulunmakta ve bu modüller arasında doğrudan entegrasyon bulunmamaktadır. ERP'nin HBYS'den farkı, bu modülleri tek bir yazılım altında toplamasıdır. ERP ile birlikte kullanıcılar birden fazla bağımsız ara yüz ile çalışma durumunda kalmamaktadır. $\mathrm{Bu}$ noktada ERP’nin HBYS'ye göre avantajları; planlama ve karar alma süreçlerinin iyileştirilmesi, raporlama ve dokümantasyonun düzenli yapılması, kurumda kullanılan teknolojilerin tek bir platformda toplanması ve bölümler arası entegrasyonun sağlanması şeklinde karşımıza çıkmaktadır. Diğer yandan, ERP uygulaması Türkiye sadece birkaç özel sağlık kuruluşunda kullanılmaktadır²5. En iyi örneklerinden bir tanesi Medical Park Hastaneler Grubu'dur. Hastane temsilcisi tarafından 2014 yılında HIMSS Türkiye kongresinde yapılan sunumda ERP sonrası kazanımlar detaylı olarak değerlendirilmiştir. Bu kazanımlardan bazıları şu şekildediri14:

- Tanımlar merkez tarafından yapılmış ve mükerrerlik sıfırlanmış,

- Tedarikçi sayısı iki yıl içerisinde 8.500 civarından 2500’e indirilmiş,

- Faturalar ile satın alma siparişleri arasında eşleştirmeler yapılabilmiş,

- İki yıl içerisinde ilaçlar ve tıbbi sarflarda karlılık \%19 oranında artmış,

- İkinci yılın sonunda merkezi anlaşma oranı \%92 olmuş ve bu durum merkezi alım gücünü artırarak kurumun pazarlık gücünü artırmış ve fiyatlarda avantaj sağlamasına neden olmuştur,

- ERP öncesi \%6-7 oranında olan sayım farkları, ikinci yılın sonunda \%1,5 oranına düşmüştür,

- Stok gün sayıları iki yıl içerisinde 40-45 gün arasından 26 güne inmiştir,

- Insan kaynakları modülleri sayesinde kariyer planlaması ve performans değerlendirme sistemi gibi süreçler daha etkin yürütülebilmiş,

- Maliyet analizleri hastane, doktor, branş, yurtiçi/yurtdışı, ayaktan/yatan, protokol ve hizmet detayında hesaplanmış ve sürekli verimlilik artışı sağlanmıştır.

\section{Sonuç ve Öneriler}

Bu derlemede sağlık kuruluşları için önemli bir verimlilik ölçütü olan kurumsal kaynak planlama (ERP) yaklaşımı değerlendirilmiştir. Bu doğrultuda ERP’nin tanımı yapılmış, 
avantajları ve dezavantajları, yazılımın seçilmesi, uygulanması ve başarısını etkileyen faktörler açıklanmış ve sağlık kuruluşlarındaki ERP süreci incelenmiştir.

Sağlık kuruluşlarındaki ERP uygulamaları ile ilgili yapılan çalışmalarda, bu sistemin sağlık hizmetleri için büyük önem arz ettiği, bu sistem ile birlikte bilgilerin zamanında ve daha erişilebilir hale geldiği, kuruma teknolojik anlamda güç kattığı, çalışanların performansını etkileyebildiği, hastaların kabulü ile ilgili süreçlerin daha iyi bir şekilde organize edildiği ve sınırlı olan kaynakların verimli bir şekilde kullanılabildiği gözlemlenmiştir4,19,20. Ayrıca derlemede ERP'nin avantajlar ile dezavantajları kısaca değerlendirilmiş ve bu sistemin hastane yöneticilerine kolaylık sağladığına, hizmetlerin daha iyi sunulması noktasında katkı yaptığına, evrak işlerini azalttığına ve toplamda kurum imajına olumlu katkı yaptığına fakat bilgilerinde şeffaf hale geldiğine ve sistemin maliyetli olduğuna vurgu yapılmıştır ${ }^{18,21}$.

Sağlık çalışanları $(n=260)$ üzerinde yapılan çalışmada ERP'nin çalışanları motive etme ve bütüncül bir bakış açısı sağlama konusunda fayda sağladığına vurgu yapılmış fakat yöneticilerin motive etme konusunda olumsuz bir yaklaşım içerişinde olduğu belirlenmiştir. $\mathrm{Bu}$ noktada üst yönetimin uygulanan bu sisteme inanması ve desteklemesi gerektiği unutulmamalıdır ${ }^{26}$. Örneğin Abukhader ${ }^{27}$ tarafından yapılan çalışmada ERP'nin özel hastanelere uygulanma süreci incelenmiş ve bu süreçte en sık seçilen kritik başarı faktörünün "üst yönetimin desteği" olduğu görülmüştür.

ERP'de dikkat edilmesi gereken bir diğer önemli husus, sağlık kuruluşları üzerindeki yaratabileceği etkidir. İngiltere'de yapılan çalışmada, örgütsel kültür ve ERP teknolojisi arasında anlamlı bir ilişki bulunmuş ve birbirlerini etkiledikleri ifade edilmiştir ${ }^{28}$. ABD'de yapılan çalışmada ERP'nin iş sürecinin yeniden yapılandırılması üzerindeki olumlu etkisi açıklanmıştır²9. Aynı şekilde, 180 hastanenin dahil olduğu bir araştırmada kurumların ERP'ye geçiş süreci ile ilgili hikayeleri incelenmiş ve bu kurumları motive eden faktörler belirlenmeye çalışılmıştır. Çalışma sonucunda elde edilen bulgulara göre kurumları motivasyona iten faktörlerin finansal, stratejik, operasyonel ve yönetsel olduğu belirlenmiştir3o.

ERP'nin bütün kurumlar için çok büyük önem arz ettiği, bilgilerin bir araya getirilmesi ve etkili bir şekilde kullanılması için kilit rol oynadığı yapılan tanımlardan anlaşılmıştır 6,7. Bu noktada ERP'nin kurum yazılımı anlamına gelmediği ifade edilmiş ve 
bu iki kavram arasındaki fark açıklanmıştır. Örneğin satış ve işlemlerin planlamasının sadece ERP ile ilgili olduğuna; malzeme ihtiyaçlarının belirlenmesinin her ikisi ile ilgili olduğuna ve alacak hesabının ise sadece kurumsal yazılımlar ile ilgili olduğuna vurgu yapılmıştır ${ }^{31}$. Ayrıca ERP'nin sağladığı avantajlar ve dezavantajlar incelenmiş ve genel olarak işlem fazlalığını, maliyeti ve hataları azalttığı; verilerin güvenliği konusunda kurumlarda tereddütler yarattığı, pahalı ve karmaşık olduğu belirtilmiştir8-11. Poston ve Grabski32 tarafından yapılan bir araştırmada ERP'nin uygulandığı kurumda üç yll sonra maliyetlerin gelirlere oranla düştüğü belirlenmiştir. Aynı şekilde, ABD’de 63 firmanın dahil olduğu bir araştırmada ERP'nin firma performansı üzerindeki etkisi incelenmiş ve ERP'nin benimsenmesinin, şirketlerin uyum sağlamayanlara göre rekabet avantajı kazanmasına yardımcı olduğu belirlenmiştir33.

Özetle, hasta ile ilgili doğru kararların doğru zamanda alınmasına etki eden faktörlerden birisi de bilginin etkili ve verimli bir şekilde eksiksiz olarak kullanılmasıdır. Bireylerin hayatlarının söz konusu olduğu bir kurumda bilginin hızlı bir şekilde elde edilmesinin ve kullanılmasının önemi ise tartışılmaz bir konudur. Yapılan bu derlemede ERP'nin özellikle hastaneler için bilginin kullanılması noktasında kuruma faydalar sağladığı ifade edilmiştir. Burada bilgilerin nerede toplandığı (bulut teknolojisi) ve şeffaflık mevzusuna ne oranda önem verildiği dikkat edilmesi gereken bir husustur. Bu bağlamda sistemi daha güvenilir kılmak adına ülkelerin kendi sağlık kurumlarının ihtiyaçlarını karşılayacak düzeyde ulusal bir yapının kullanımının desteklenmesi ve ülke genelindeki tüm sağlık kuruluşlarında etkili bir şekilde kullanımının sağlanması önerilebilir.

\section{KAYNAKLAR}

1. Fiaz M, Ikram A, Ilyas A. Enterprise resource planning systems: Digitization of healthcare service quality. Administrative Sciences. 2018;8(3):1-12. doi:10.3390/admsci8030038.

2. Goldschmidt-Clermont PJ. COVID-19 real-world data for the US and lessons to reopen business. PLoS Pathogens. 2020;16(8):1-7. doi:10.1371/journal.ppat.1008756.

3. Obrenovic B, Du J, Godinic D, Tsoy D, Khan MAS, Jakhongirov I. Sustaining enterprise operations and productivity during the COVID-19 pandemic: 
"Enterprise Effectiveness and Sustainability Model”. Sustainability. 2020;12(15):127. doi:10.3390/su12155981.

4. Lee CW, Kwak N. Strategic enterprise resource planning in a health-care system using a multicriteria decision-making model. Journal of Medical Systems. 2011;35(2):265-275. doi:10.1007/s10916-009-9362-x.

5. Costa CJ, Aparicio M, Raposo J. Determinants of the management learning performance in ERP context. Heliyon. 2020;6(4):1-10. doi:10.1016/j.heliyon.2020.e03689.

6. Al-Mashari M, Al-Mudimigh A, Zairi M. Enterprise resource planning: A taxonomy of critical factors. European Journal of Operational Research. 2003;146(2):352364. doi:10.1016/So377-2217(02)00554-4.

7. Ragowsky A, Somers T. Enterprise resource planning. Journal of Management Information Systems. 2002;19(1):11-15. doi:10.1080/07421222.2002.11045718.

8. Hossain L, Patrick JD, Rashid MA. Enterprise Resource Planning: Global Opportunities and Challenges: Global Opportunities and Challenges. London: Idea Group Publishing; 2001.

9. Gupta A. Enterprise resource planning: the emerging organizational value systems. Industrial Management \& Data Systems. 2000;100(3):114-118. doi:1108/02635570010286131.

10. Hofmann P, Woods D. Cloud computing: The limits of public clouds for business applications. IEEE Internet Computing. 2010;14(6):90-93. doi:10.1109/MIC.2010.136.

11. Peng GCA, Gala C. Cloud ERP: a new dilemma to modern organisations? Journal of Computer Information Systems. 2014;54(4):22-30. doi:10.1080/08874417.2014.11645719.

12. Monk E, Wagner B. Concepts in enterprise resource planning. Boston:Cengage Learning; 2012.

13. Umble EJ, Haft RR, Umble MM. Enterprise resource planning: Implementation procedures and critical success factors. European Journal of Operational Research. 2003;146(2):241-257. doi:10.1016/So377-2217(02)00547-7.

14. Usta A. Medical Park’ta kurumsal kaynak yönetimi. In: HIMSS Türkiye; 4-5 Haziran 2014; İstanbul, Türkiye. 
15. Somers T, Nelson K. The impact of critical success factors across the stages of enterprise resource planning implementations. In Proceedings of the 34th Annual Hawaii International Conference on System Sciences; 2001, January; IEEE.

16. Ehie IC, Madsen M. Identifying critical issues in enterprise resource planning (ERP) implementation. Computers in Industry. 2005;56(6):545-557. doi:10.1016/j.compind.2005.02.006.

17. Bradford M, Florin J. Examining the role of innovation diffusion factors on the implementation success of enterprise resource planning systems. International Journal of Accounting Information Systems. 2003;4(3):205-225. doi:10.1016/S1467-0895(03)00026-5.

18. Mucheleka M, Halonen R. ERP in Healthcare. Proceedings of the 17th International Conference on Enterprise Information Systems. 2015:162-171. doi:10.5220/0005376801620171.

19. Roth AV, Van Dierdonck R. Hospital resource planning: concepts, feasibility, and framework. Production and Operations Management. 1995;4(1):2-29. doi:10.1111/j.1937-5956.1995.tboo038.x.

20. Merode GG, Groothuis S, Hasman A. Enterprise resource planning for hospitals. International Journal of Medical Informatics. 2004;73(6):493-501. doi:10.1016/j.ijmedinf.2004.02.007.

21. Sanja MM. Impact of enterprise resource planning system in health care. International Journal of Academic Research in Business and Social Sciences. 2013;3(12):404-418. doi:10.6007/IJARBSS/v3-i12/438.

22. Shohet IM, Nobili L. Enterprise resource planning system for performance-basedmaintenance of clinics. Automation in Construction. 2016;65:33-41. doi:10.1016/j.autcon.2016.01.008.

23. Rodriguez T, Escobar PB, Monge LP. Technical and organisational aspects in enterprise resource planning systems implementation: lessons from a Spanish public hospital. Enterprise Information Systems. 2014;8(5):533-562. doi:10.1080/17517575.2012.713122.

24. Ayani S, Mirzaei M, Abbasi N, Moulaei K. Enterprise resource planning in the health industry: Problems of its usage based on the extent of the countries' development. Applied Medical Informatics. 2021;43(1):1-13. 
25. Sevim E, Önder E, Nal M. Sağlık Sektöründe Kurumsal Kaynak Planlama Sistemleri. In: 1st International Health Sciences and Life Congress; 2018; Burdur, Turkey.

26. Sia SK, Tang M, Soh C, Boh WF. Enterprise resource planning (ERP) systems as a technology of power: empowerment or panoptic control?. ACM SIGMIS Database: the DATABASE for Advances in Information Systems. 2002;33(1):23-37. doi:10.1145/504350.504356.

27. Abukhader SM. ERP implementation in the private hospitals of Saudi Arabia. International Journal of Healthcare Management. 2015;8(2):77-88. doi:10.1179/2047971914Y.oooooooo92.

28. Kayas OG, McLean R, Hines T, Wright GH. The panoptic gaze: Analysing the interaction between enterprise resource planning technology and organisational culture. International Journal of Information Management. 2008;28(6):446-452. doi:10.1016/j.ijinfomgt.2008.08.005.

29. Huq Z, Martin TN. The recovery of BPR implementation through an ERP approach. Business Process Management Journal. 2006;12(5):576-587. doi:10.1108/14637150610691000.

30. Nzaou P, Uwizeyemungu S, Raymond L, Paré G. Motivations underlying the adoption of ERP systems in healthcare organizations: Insights from online stories. Information Systems Frontiers. 2014;16(4):591-605. doi:10.1007/s10796-0129361-1.

31. Wallace TF, Kremzar MH. ERP: Making thappen: the implementers' guide to success with enterprise resource planning. John Wiley \& Sons; 2002.

32. Poston R, Grabski S. Financial impacts of enterprise resource planning implementations. International Journal of Accounting Information Systems. 2001;2(4):271-294. doi:10.1016/S1467-0895(01)00024-0.

33. Hunton JE, Lippincott B, Reck JL. Enterprise resource planning systems: comparing firm performance of adopters and nonadopters. International Journal of Accounting information systems. 2003;4(3):165-184. doi:10.1016/S1467o895(03)oooo8-3. 